\title{
Perfil etiológico e epidemiológico das vulvovaginites que acometem mulheres em uma cidade do estado de Tocantins
}

\author{
Etiological and epidemiological profile of vulvovaginites that encourage women in a city in \\ the state of Tocantins
}
Perfil etiológico y epidemiológico de las vulvovaginitas que animan a las mujeres en una ciudad del estado de Tocantins

Geisa Barbosa Alves ${ }^{1 *}$, Mariana Caroline Tocantins Alvim¹, Valdir Francisco Odorizzi ${ }^{1}$, Ana Kleiber Pessoa Borges ${ }^{1}$, Anderson Barbosa Baptista ${ }^{1}$.

\begin{abstract}
RESUMO
Objetivo: Analisar a etiologia e a epidemiologia da microbiota vaginal das mulheres de uma cidade do estado do Tocantins. Métodos: As amostras coletadas foram cultivadas em meio Ágar Sangue enriquecido com Ágar Base Columbia em atmosfera microaerófila e Ágar Sabouraud Dextrose. Foram incubadas a $35^{\circ} \mathrm{C}$ por 60 horas para diferenciar contaminantes GRAM negativos utilizou-se o Ágar Macconkey. Foram produzidos esfregaços com coloração de GRAM. As amostras com crescimento de colônias no Ágar Sangue foram submetidas ao teste de catalase e, posteriormente, teste de fermentação de açucares, utilizando o meio Triple Sugar Iron. Para a diferenciação de leveduras, as colônias passaram pela Prova do Tubo Germinativo. Resultados: Foram identificadas a bactéria Gardnerella vaginalis e o fungo Candida albicans em $4 \%$ e $7 \%$, respectivamente. Detectamos a presença de cocos e diplococos Gram positivo, lactobacilos, bacilos curtos e células leveduriformes. Conclusão: Contribuiu para a compreensão do perfil epidemiológico da saúde vaginal das mulheres dessa região, uma vez que em todo o estado não há estudos da microbiota vaginal, suprindo a carência de conhecimento científico regional sobre a ocorrência destas doenças e, consequentemente, a melhoria dos serviços de saúde prestados a essas pacientes.
\end{abstract}

Palavras-chave: Candida albicans, Gardnerella vaginalis, Candidíase.

\begin{abstract}
Objective: To analyze the etiology and epidemiology of the vaginal microbiota of women from a city in the state of Tocantins. Methods: The samples were grown on Blood Ágar medium enriched with Columbia Base Ágar in a microaerophilic atmosphere and Sabouraud Dextrose Ágar. They were incubated at $35^{\circ} \mathrm{C}$ for $60 \mathrm{~h}$ and to differentiate negative GRAM contaminants used MacConkey Ágar. There were sales smears with GRAM. Samples with colony growth on Blood Ágar were subjected to the catalase test and, later, sugar fermentation test, of three sugars, using the Triple Sugar iron medium. For yeast differentiation, the colonies passed the Germ Tube Test. Results: The bacteria Gardnerella vaginalis and the fungus Candida albicans were identified in $4 \%$ and $7 \%$, respectively. We detected the presence of Gram-positive cocci and diplococci, lactobacilli, short bacilli, and yeast cells. Conclusion: it contributed to the understanding of the epidemiological profile of the vaginal health of women in this region, since in the entire state there are no studies of the vaginal microbiota, filling the lack of regional scientific knowledge about the occurrence of these diseases and, consequently, the improvement of health services provided to these patients.
\end{abstract}

Keywords: Candida albicans, Gardnerella vaginalis, Candidiasis.

\section{RESUMEN}

Objetivo: Analizar la etiología y epidemiología de la microbiota vaginal de mujeres de una ciudad del Estado de Tocantins. Métodos: Las muestras recolectadas se cultivaron en medio Blood Ágar enriquecido con Columbia Base Ágar en una atmósfera microaerofílica y Sabouraud Dextrose Ágar. Se incubaron a 35 C durante 60 hy se utilizó Ágar Macconkey para diferenciar los contaminantes GRAM negativos. Se produjeron frotis con tinción GRAM. Las muestras con crecimiento de colonias en Blood Àgar se sometieron a la prueba

1 Universidade Federal do Tocantins (UFT), Palmas - TO. *E-mail: geisamaytebarbosa@hotmail.com 
de catalasa y, posteriormente, a la prueba de fermentación del azúcar, utilizando Triple Sugar Iron. Para la diferenciación de levaduras, las colonias pasaron la prueba del tubo germinativo. Resultados: Las bacterias Gardnerella vaginalis y el hongo Candida albicans en $4 \%$ y $7 \%$, respectivamente. Detectamos la presencia de cocos y diplococos Gram positivos, lactobacilos, bacilos cortos y células de levadura. Conclusión: Contribuyó al conocimiento del perfil epidemiológico de la salud vaginal de las mujeres de esta región, ya que en todo el estado no existen estudios del microbiota vaginal, supliendo la falta de conocimiento científico regional sobre la ocurrencia de estas enfermedades y, en consecuencia, la mejora de los servicios de salud que se brindan a estos pacientes.

Palabras clave: Candida albicans, Gardnerella vaginalis, Candidiasis.

\section{INTRODUÇÃO}

Vulvovaginite é uma condição que envolve processos inflamatórios ou infecciosos da vulva e da parede vaginal, que pode ocorrer em qualquer idade, principalmente na pós-menopausa, na qual ocorre um desequilíbrio hormonal. Sua etiologia está associada a causas intrínsecas, como um desequilíbrio da microbiota local, devido, muitas vezes, ao uso de antibióticos; e por causas extrínsecas, como irritantes químicos ou as dermatoses, devido, por exemplo, aos sabonetes, cremes e absorventes íntimos. As vulvovaginites estão intimamente ligadas aos cuidados com a genitália, representando a principal reclamação das pacientes nos consultórios ginecológicos (FELIX TC, 2019; GOJE O e MUNOZ JL, 2017).

A candidíase é responsável por $20 \%$ a $25 \%$, a tricomoníase por 15 a $20 \%$ dos casos e as não infecciosas de $5 \%$ a $10 \%$, nas vaginites. É importante frisar que o exame físico, achados laboratoriais e o histórico devem ser utilizados para o diagnóstico (PALADINE HL, 2018). Um estudo realizado em Santa Catarina durante o ano de 2018 mostrou que essa doença está presente em maior número $(38,9 \%)$ nas mulheres grávidas, gerando complicações mais graves nesse grupo, como crescimento intrauterino restrito, trabalho de parto prematuro, gerando baixo peso ao nascer, endometrite, rotura prematura de membranas, corioamnionite, infecções puerperais e até mesmo aborto, além de se poder constituir uma porta de entrada para vírus da imunodeficiência humana (HIV), vírus B da hepatite (HBV) e outros patógenos, tanto para grávidas, como para não grávidas (NUNES RD, et al., 2018; BOATTO HF, et al., 2007; FEBRASGO, 2010).

Dentre as vulvovaginites mais comuns, destaca-se a candidíase vulvovaginal, a qual é uma doença inflamatória aguda, definida como uma infecção da mucosa genital, causada, principalmente, pela levedura oportunista $C$. albicans que se transforma de um comensal vaginal em um patógeno agressor. As pacientes com candidíase podem cursar com um quadro assintomático ou com sintomas clínicos, como a dispareunia, leucorréia e prurido, que varia de leve a intenso (RODRIGUES MT, et al., 2013).

Dessa forma, o diagnóstico é clínico através da queixa dessas pacientes, onde relatam a presença de prurido, podendo estar acompanhado de corrimento amarelado ou branco/acinzentado e odor fétido. Esses sintomas são investigados através do exame ginecológico da vagina, vulva e também do colo uterino. Além disso, os exames laboratoriais sorológicos, citopatológicos e Papanicolau do colo uterino, através do exame a fresco e cultura microbiológica, contribuem para o rastreamento de doenças sexualmente transmissíveis, diagnosticando e tratando corretamente o problema (ALVES J, et al., 2016).

A C. albicans possui a capacidade de autotransformação morfogenética, que permite a ela uma capacidade de mutação e, de adaptação ambiental, que é responsável por permitir a transformação de comensal favorável a microbiota, para um patógeno agressor. A C. albicans está presente na microbiota vaginal do hospedeiro como um comensal na forma morfogenética $Y$, auxiliando a homeostasia imune local. Quando ocorre um desequilíbrio, a forma $\mathrm{Y}$ se modifica para a forma $\mathrm{H}$, que é a forma responsável pela patogenicidade da levedura, pois ocorre a formação de um biofilme fortemente aderido ao epitélio da vagina, gerando a candidíase vaginal (HARRIOT MM, et al., 2010).

Outra vulvovaginite bastante frequente consiste na vaginose bacteriana (BV), caracterizada por um desequilíbrio da microbiota vaginal normal, com diminuição acentuada ou desaparecimento de lactobacilos acidófilos (Lactobacilos) e aumento de bactérias anaeróbias, em especial de Gardnerella vaginalis (ALBORGHETTI G, et al., 2007; ALMEIDA MS, et al., 2013). Espécie bacteriana comum na microbiota vaginal 
e pode ser encontrada em muitas mulheres saudáveis. Porém, em mulheres que apresentam BV pode ser quantitativamente maior, quase onipresente, pois possui citotoxicidade e adesão maior ao epitélio em relação às outras bactérias, além de ter uma maior propensão a formar biofilme, facilitando a fixação de outras espécies bacterianas, e passível de transmissão sexual (SHIPITSYNA E, et al., 2019).

Essa bactéria modifica o pH vaginal e se caracteriza como cocos-bacilos curtos, Gram-negativos ou Gramvariáveis, pleomórficos, não capsulados, imóveis e anaeróbicos facultativos (OLIVEIRA AB, et al., 2007). Para o diagnóstico de BV, Nugent RP, et al. (1991), desenvolveram um critério que consiste na coloração pelo Gram de esfregaço do conteúdo vaginal, com contagem dos morfotipos de lactobacilos, Gardnerellas/Bacteroides e Mobiluncus existentes, considerando os tipos morfológicos e quantificando em cruzes de $1 \mathrm{a} 4$, por campo, em aumento de 100X no microscópio. Considera-se a BV com escore 7 ou acima de 7. Um escore de 4 a 6 é considerado intermediário e um de 0 a 3 é considerado normal.

No Brasil, a BV se mostra muito frequente, atingindo cerca de $45 \%$ das mulheres com queixa de corrimento vaginal, podendo estar presente, também, mesmo em mulheres assintomáticas, afetando cerca de $10 \%$ a $30 \%$ das gestantes e 10\% das mulheres atendidas na atenção básica (NICOLETTI GP, et al., 2019). Assim, tendo em vista o difícil acesso das mulheres de baixa renda ao diagnóstico e tratamento adequado das vulvovaginites devido, principalmente, ao medo do exame e do resultado, o atendimento rápido e impessoal, a relação autoritária da equipe com as pacientes, espaço inadequado, o tempo de espera para o atendimento, a emissão de resultados e a marcação das consultas são alguns outros motivos apontados pela literatura que desencorajam uma consulta ginecológica (CARVALHO JAM e BRITO FA, 2005).

É necessário fazer a identificação do agente etiológico, e assim, tratar conforme for. O tratamento sistêmico pode ser adotado, principalmente em infecções mistas e em crianças e mulheres sem vida sexual ativa. A candidíase não complicada, causa mais frequente das vulvovaginites, pode ser tratada com dose única, via oral, de azóis, apresentando taxas de cura de aproximadamente de $90 \%$. O uso de pomadas e cremes tópicos pode também ser utilizado, principalmente em grávidas, sempre com prescrição médica. É preciso também tratar os fatores predisponentes, como a diabetes mellitus descontrolada, doenças autoimunes, controle de doenças como HIV, entre outros (FEBRASGO, 2010).

O presente trabalho propõe analisar a etiologia e a epidemiologia da microbiota vaginal de um grupo de mulheres residentes em uma cidade do Estado de Tocantins.

\section{MÉTODOS}

Foram coletadas 74 amostras de secreção vaginal, entre agosto de 2018 e agosto de 2019. Foram incluídas na pesquisa mulheres que apresentavam ou não sintomatologia de vulvovaginites em diferentes idades, entre 15 e 40 anos, fases reprodutivas e grávidas, que buscavam o serviço ginecológico durante esse período. Foram excluídas mulheres que estavam em período menstrual. Para a coleta utilizou-se um swab estéril e meio de transporte ágar Stuart. As amostras coletadas foram cultivadas em meios seletivos para crescimento de Gardnerella e Leveduras em meio ágar Sangue enriquecido com Ágar Base Columbia e Ágar Sabouraud Dextrose e incubadas a $35^{\circ} \mathrm{C}$ por $60 \mathrm{~h}$ e incubadas em jarra com atmosfera microaerófila, e para diferenciar contaminantes GRAM negativos utilizou-se o Ágar MacConkey. Na sequência foram produzidos esfregaços em lâmina de vidro e aplicada à coloração de GRAM. As amostras com crescimento de colônias no ágar sangue foram submetidas ao teste de catalase, para diferenciar estafilococos e estreptococos, e 0 teste de fermentação de três açúcares glicose, lactose e sacarose, utilizando o meio Triple Sugar Iron. Para a diferenciação de leveduras, crescimento em Sabouraud, foi realizada a Prova do Tubo Germinativo, utilizando $1 \mathrm{~mL}$ de soro humano e incubada a $35-37^{\circ} \mathrm{C}$ por $2 \mathrm{~h}$. Após este período, uma lâmina foi preparada para visualizar a presença do tubo germinativo no microscópio óptico (KONEMAN EW, et al., 2008).

Os dados foram digitados em planilha do software Excel e os valores absolutos foram convertidos em porcentagens para elaboração de gráficos, e determinação de média. Esta pesquisa seguiu em todos os seus estágios os princípios éticos para pesquisas envolvendo seres humanos descritos pela resolução do conselho nacional de saúde № 466, de 12 de dezembro de 2012, e foi realizado após a aprovação do Comitê de Ética em Pesquisa, sob número CAAE 91394418.5.0000.5519. 


\section{RESULTADOS E DISCUSSÃO}

Foram coletadas 74 amostras de secreção vaginal no total, nas quais 56 dessas foram preparados esfregaços, e esse número se diferiram do total devido ao comprometimento de 18 lâminas que ficaram impossibilitadas de leitura, no entanto não foi observado nenhum crescimento bacteriano ou fúngico dessas nos meios específicos. A idade média das pacientes foi de 23 anos, e apenas 3 delas apresentaram sintomas de infecções vaginais ainda não tratadas, como prurido e corrimento vaginal, iniciado há uma semana, porém os resultados entre essas participantes e as demais, que não relataram sintomas da doença, e apenas uma das três pacientes sintomáticas apresentaram resultado laboratorial condizente com a doença estudada. $O$ primeiro resultado mostra uma análise geral do crescimento microbiano no esfregaço sanguíneo visto em microscópio óptico, referente a essas amostras coletadas via "Swab" do conteúdo vaginal (Figura 1 e 2).

Figura 1 - Análise, em porcentagem, no microscópio óptico das 56 amostras coletadas da microbiota vaginal via Swab.

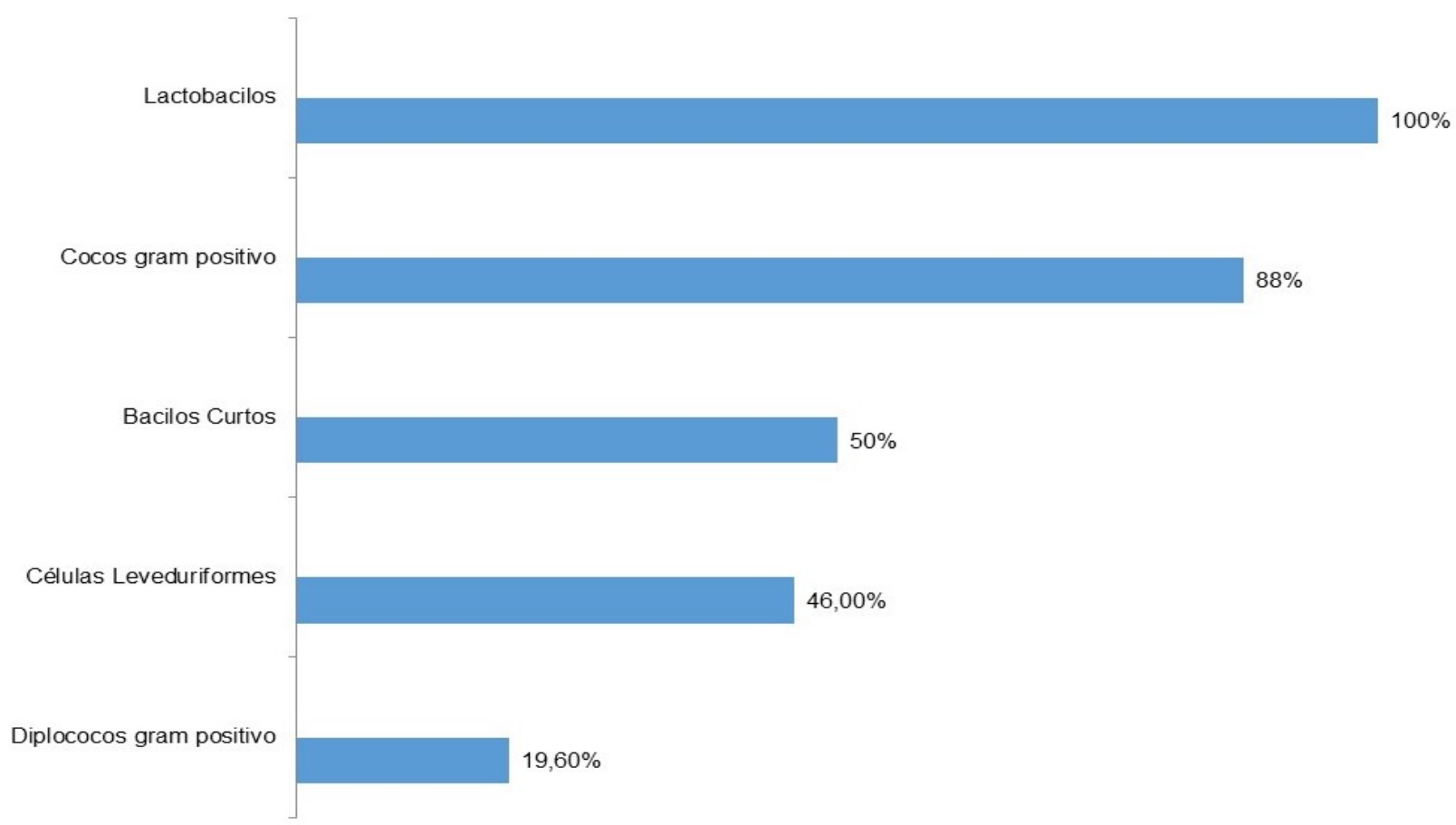

Fonte: Alves GB, et al., 2020.

Figura 2 - Morfotipos encontrados em 56 amostras, em números absolutos, por coloração GRAM de amostras coletadas da microbiota vaginal via "Swab".

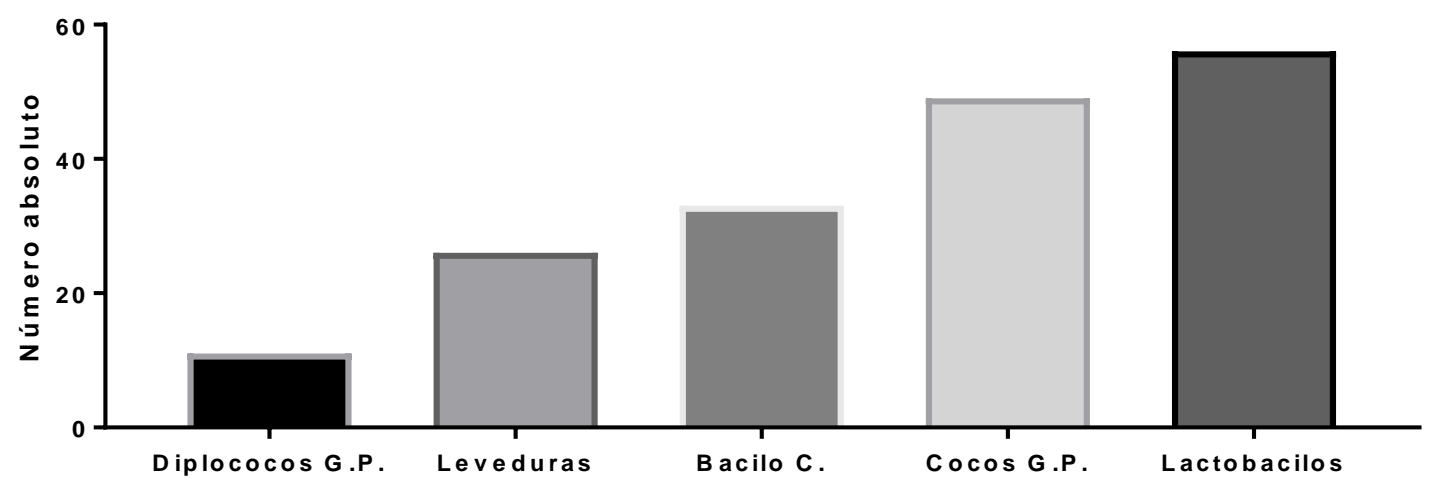

Legenda: Diplococos G.P: Diplococos gram positivo; Células Leveduriformes; Bacilo C: Bacilo Curto; Cocos G.P: Cocos gram positivo e Lactobacilos. Fonte: Alves GB, et al., 2020. 
No referido estudo foi observado que em todas as amostras havia a presença de lactobacilos, mas em quantidades diferentes, entre as quais $44,6 \%$ das amostras apresentaram número de Lactobacilos inferior ao dos demais componentes dessas amostras e essa condição favoreceram o aumento de outros morfotipos, podendo predispor a processos patológicos, conforme ilustrado nas Figuras 3 e 4 . Nota-se a presença de associação entre cocos gram positivos, leveduras e cocobacilos em 2 amostras. Ficou evidenciado que uma média de 6,7 mulheres, $12 \%$ das pacientes, apresentou predominância de desequilíbrio na microbiota. Porém, esse quadro ainda é melhor do que quando comparado com um estudo realizado em Pernambuco com 277 mulheres, no qual apenas $32,1 \%$ apresentaram a presença de lactobacilos, podendo estar passando ou indicativo de que essas mulheres passarão por infecções vaginais (Figura 3 e 4) (LEITE SF, et al., 2010).

Figura 3 - Representação em número absoluto em 56 amostras, relacionando a diminuição dos Lactobacilos e a predominância de outros morfotipos.

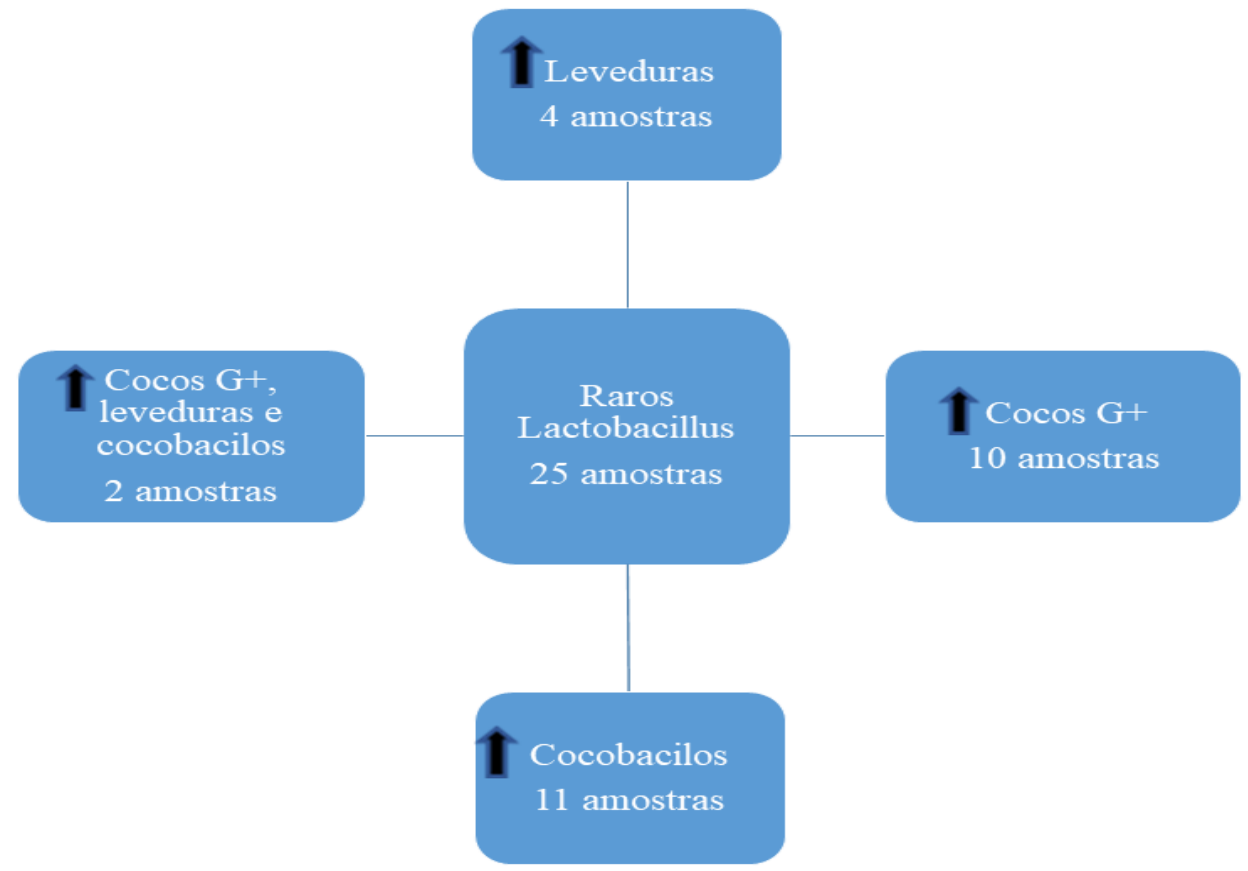

Fonte: Alves GB, et al., 2020.

Figura 4 - Relação entre a predominância de lactobacilos ou outros morfotipos em 56 amostras.

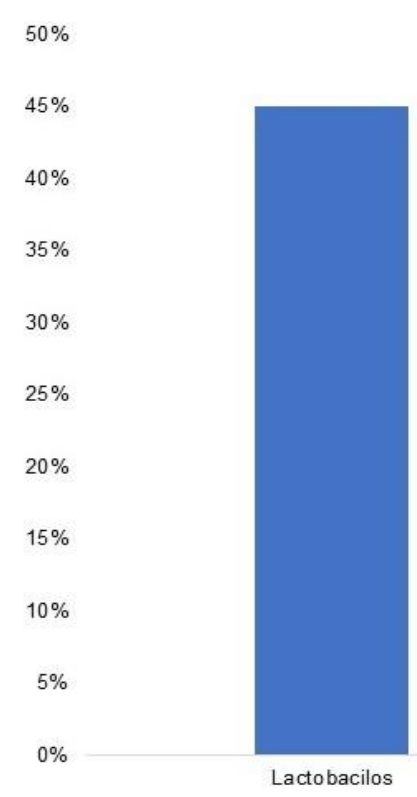

Fonte: Alves GB, et al., 2020.

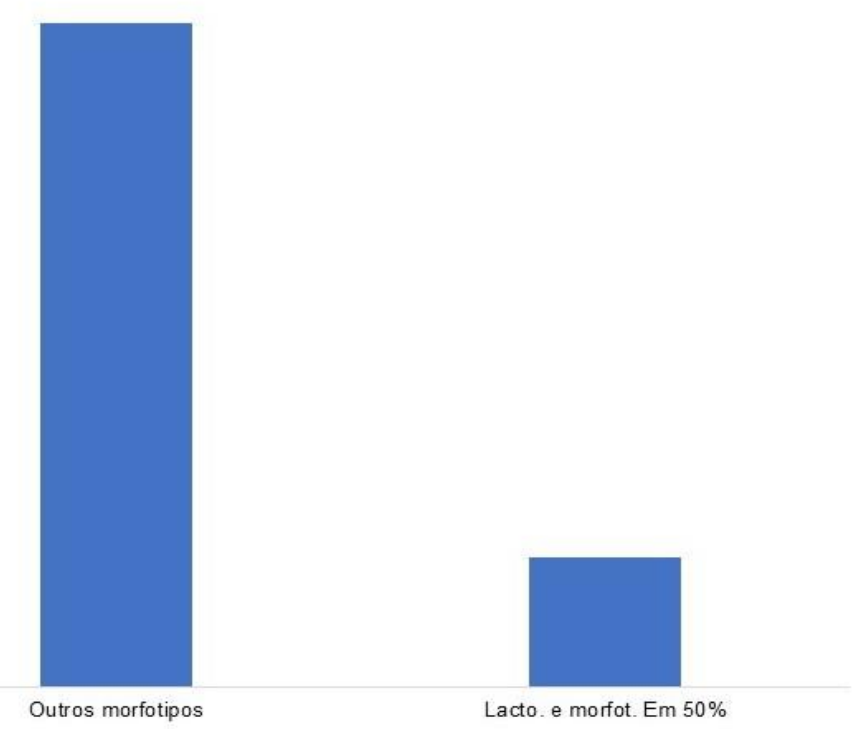


Importante considerar que a VB é caracterizada por um desequilíbrio da microbiota vaginal, na qual ocorre uma diminuição dos lactobacilos, favorecendo o desenvolvimento de cepas oportunistas (RESENDE AF, et al., 2019). Os principais microrganismos são a bactéria $G$. vaginallis e infecções fúngicas, principalmente pela C. albicans (DUARTE G e LANDRES DV, 1998).

Fatores como o uso de contraceptivos, gravidez, variações hormonais ocorridas nas diferentes fases do ciclo menstrual, ducha, sabonete íntimo e alguns medicamentos, como os antibióticos, promovem a diminuição dos Lactobacilos, que são responsáveis pelo pH ácido da vagina, através da produção de ácido láctico e peróxido de hidrogênio, gerando, assim, variações no $\mathrm{pH}$ vaginal e, consequentemente, na composição da microbiota local, pois a produção de ácido lático é essencial para a inibição dos microrganismos patológicos. Assim, através da análise no microscópio óptico, é possível detectar a presença de patologias, avaliando a predominância de cada conteúdo presente sobre a microbiota, e, claro, a comparação entre eles. Em uma amostra que corresponde à saúde vaginal indicativa como normal, é necessário que a quantidade de lactobacilos seja quantitativamente maior que a dos demais componentes coletados (BRASIL, 2015).

Outra parte do estudo foi responsável por analisar 74 amostras que foram semeadas em meio ágar Sangue, e isso permitiu a identificação de $33,4 \%$ colônias com a presença de beta-hemólise, sugestivo de $G$. vaginalis, assim como o crescimento de bactérias contaminantes que predominam na região vaginal externa e da microbiota intestinal normal, como a bactéria Proteus mirabilis, que é uma enterobactéria Gram negativa, que possui grande motilidade, e está amplamente distribuída pelo meio ambiente, em matéria orgânica, no solo e na água (MICHELIM L, 2008). O Teste de Catalase executado em 33,4\% das amostras que apresentaram crescimento bacteriano característico de G. vaginalis, obteve resultado negativo em $28 \%$, delas, descartando as demais que apresentaram resultado positivo do diagnóstico de G. vaginalis, uma vez que o padrão de resposta a esse teste da bactéria em estudo é o resultado negativo. Das 7 amostras que apresentaram catalase negativa, três delas foram positivas quanto à fermentação dos açúcares presentes no meio, sugerindo a presença da bactéria $G$. vaginalis em $4 \%$ das amostras avaliadas.

Esses resultados sugerem que apesar da cultura apresentar apenas 3 amostras sugestivas de G. vaginalis, o Gram pode ser um aliado importante para verificar o comportamento da microbiota, pois a média de mulheres com desequilíbrio da microbiota é maior que resultados de cultura positivo, no entanto, sugere que o baixo resultado em cultura pode ser devido ao uso de algum inibidor, como medicamentos. As principais características bioquímicas desta bactéria destacam-se, além da catalase (-), a fermentação de açúcares utilizando o Triple Sugar Iron Ágar (TSI). Um estudo realizado em Pernambuco revelou uma maior incidência dessa bactéria nas culturas, pois identificou a presença de $G$. vaginalis em $96,8 \%$ das 277 amostras, número maior quando comparado ao atual estudo e ao citado anteriormente (LEITE SF, et al., 2010).

A Universidade Estadual de Maringá (UEM) realizou entre janeiro de 2002 a dezembro de 2006, exames de papanicolau e os achados acordaram com o descrito na literatura, de que aproximadamente $50 \%$ das mulheres são assintomáticas para a VB, pois observaram nesse estudo que, $5 \%$ do total das 1531 amostras analisadas apresentaram resultado positivo para VB, causado principalmente pela G. vaginalis, 79,22\%, sendo que 59,7\% apresentaram a forma assintomática da doença (TONINATO LG, et al., 2016).

Esses resultados são maléficos para a população feminina, pois o fato de não apresentar sintomas da doença dificulta a busca dessas pacientes ao serviço de saúde, para realizar tratamentos de possíveis desequilíbrios da saúde vaginal, e, consequentemente, evitar futuras comorbidades. Outro estudo realizado pela Universidade Federal de Juiz de Fora revelou que, das 89 amostras coletadas, foi possível realizar o isolamento de $G$. vaginalis em $47 \%$, com identidade confirmada pela técnica de Reação em Cadeia de Polimerase (PCR) - uma porcentagem maior do que os achados no presente trabalho.

A cultura microbiológica não é muito específica para a bactéria $G$. vaginalis, além de ser um método diagnóstico caro para a prática de rotina. Ainda assim, a presença deste microrganismo foi detectada em aproximadamente $50 \%$ dessas amostras. Além disso, os métodos moleculares foram utilizados, por meio do qual uma incidência maior do patógeno foi apresentada em relação à cultura microbiológica: $70 \%$ de $G$. vaginalis nas amostras de secreções vaginais (BRASIL, 2015). 
A Gardnerella vaginalis é uma das principais espécies de bactérias responsáveis pela BV e está presente no trato genital feminino de forma não patológica (FERRIS MJ, et al., 2004; MOODLEY P, 2002). É fundamental para o equilíbrio e homeostase da vagina, porém em alguns momentos ela adquire a capacidade de se tornar suficientemente agressiva, se tornando predominante na flora vaginal, gerando o rompimento do equilíbrio microbiano local, sendo responsável por intercorrências infecciosas como a VB (LEPARGNEUR JP e ROUSSEAU V, 2002).

Essa bactéria é um microrganismo fastidioso, podendo não crescer nos meios de cultura habituais ou requerer maior tempo de incubação (OLIVEIRA AB, et al., 2007). A característica marcante dela é apresentar reação ao Gram variável. $O$ fato ocorre devido à fina camada de peptideoglicano encontrada, o que permite a identificação de diferentes Gram isolados de G. vaginalis, como Gram positivos, Gram negativos ou Gram variáveis. É de fundamental importância a realização de exames para diagnóstico da prevalência desse processo patológico, pois $G$. vaginalis apresenta sintomatologia muito incômoda para as mulheres (FIGUEIREDO PG, 2006). O Sistema de Bethes de 2001 traz como critérios para o diagnóstico de VB, a presença cluecells, de um fundo de lâmina constituído por uma fina camada de cocobacilos, e ausência de lactobacilos (CARVALHO MGD, 2005). A coloração pelo Gram além de ser simples, é o melhor exame para o diagnóstico de $V B$ e é preferível à cultura porque é mais específico e disponível facilmente nos laboratórios (LIMA EA, et al., 2019).

Dentre os sintomas mais comuns, temos o corrimento vaginal desagradável com odor fétido que se acentua durante a relação sexual e menstruação, podendo causar transtornos psicossociais a essas mulheres (LINHARES LM, et al., 2010). Além da sintomatologia, uma infecção não tratada corretamente pode causar um conjunto de complicações, como a infertilidade, o aborto e parto prematuro, aumento do risco de infecção pelo vírus da imunodeficiência humana (HIV) e infecções sexualmente transmissíveis (IST's), como tricomoníase e gonorréia, elevando também o risco de doenças inflamatórias pélvicas (RIBEIRO AA, et al., 2007).

A análise do crescimento de colônias leveduriformes ocorreu em 19\% das amostras clínicas que foram inoculadas em meio de cultura Ágar Sabouraud. Um estudo realizado pelo Laboratório Municipal de Fraiburgo, em Santa Catarina, foi observado uma maior incidência de Candida spp., quando comparado a este estudo, pois dos 451 exames de secreção vaginal coletados $12 \%$ dos exames apresentaram G. vaginalis, $7 \%$ casos de Candida spp., $3 \%$ casos de Trichomonas spp. e $22 \%$ dos exames apresentam resultado positivo para vulvovaginites (AMARAL AD, 2012).

As técnicas para identificação das espécies de Candida são baseadas em métodos bioquímicos, como fermentação de carboidratos, e a capacidade da formação de tubos germinativos (SILVA CHPM e NEUFELD PM, 2006). A prova do tubo germinativo foi escolhida para identificar e diferenciar a espécie $C$. albicans das outras espécies do gênero, por ser um teste rápido, com baixo custo e de fácil execução. Foi possível observar o crescimento do tubo germinativo em $28,5 \%$ das amostras que apresentaram crescimento de leveduras no meio de cultura e $7 \%$ na totalidade de amostras coletadas, confirmando C. albicans. Em Pernambuco apenas $5,1 \%$ das 277 amostras apresentou resultado positivo para o crescimento de fungos em meio de cultura, número inferior quando comparado ao atual estudo (LEITE SF, et al., 2010).

A C. albicans é encontrada em $10 \%$ a $20 \%$ das mulheres em idade reprodutiva, porém em baixa quantidade, o que faz com que a mulher portadora não tenha sintomas até que ocorra uma interferência na microbiota vaginal, como uma imunossupressão local, que facilita o aparecimento dos sintomas, como observado no atual estudo, na qual 3 mulheres em idade reprodutiva que testaram positivo para $C$. albicans, queixaram-se de sintomas comuns observados na candidíase vaginal, devido ao uso pregresso de antibióticos. Outras espécies desse gênero também apresentam resultado positivo para esta prova $(C$. stellatoidea e $C$. dublinensis). Para realizar a diferenciação entre essas espécies que apresentam o padrão positivo para a presença do tubo germinativo, é necessário utilizar de técnica de PCR, porém, é uma técnica com custos elevados o que inviabiliza a execução da mesma (LARSSON PG, et al., 2005).

Um estudo retrospectivo transversal realizado entre Janeiro de 2009 e Dezembro de 2011, envolvendo 2677 mulheres de idade entre 15 e 49 anos, no Hospital Geral em St George's, em Granada, apresentou 
achados leveduriformes inferiores quando comparado ao atual estudo, pois apenas $3,6 \%$ apresentaram Candida vaginalis, porém não foi realizado testes de identificação da espécie predominante nas amostras, impossibilitando a comparação entre as espécies encontradas (BROOKS SLK e RODRIGO S, 2013).

Alguns lactobacilos são produtores de peróxido de hidrogênio que reduzem citocinas pró-inflamatórias vaginais e todos estão adaptados ao $\mathrm{pH}$ baixo capaz de inibir a proliferação bacteriana patogênica, para tanto está claro que o desequilíbrio da microbiota é característica fundamental para o desenvolvimento de vaginose. É importante destacar que transmissões sexuais, especialmente em portadores do vírus do HIV, incrementam o desenvolvimento da patologia (PAAVONEN J e BRUNHAM RC, 2018).

\section{CONCLUSÃO}

A presente pesquisa contribuiu para a compreensão do perfil epidemiológico da saúde vaginal das mulheres de uma cidade do Tocantins, uma vez que em todo o estado não há estudos da microbiota vaginal, permitindo assim a melhoria dos serviços de saúde prestados a essas pacientes. Pode-se concluir que, os testes aplicados identificaram a presença da bactéria $G$. vaginalis em $4 \%$ e Candida albicans em $7 \%$ das amostras avaliadas. Em 25 amostras, identificamos que os lactobacilos estavam reduzidos e essa condição favoreceu o aumento de outros morfotipos, como cocos e diplococos gram positivo, bacilos curtos e células leveduriformes em quantidades diferentes dentro do conjunto de amostras avaliadas. Esse trabalho propõe a adoção da realização do exame de GRAM, que além de ser rápido, possui baixo custo, e pode ser feito a partir de esfregaços das amostras vaginais coletadas periodicamente em mulheres assintomáticas e sintomáticas nos consultórios ginecológicos, prevenindo e detectando morfologias que causam infecções vaginais e também câncer de colo uterino, que é responsável pelo óbito de 265 mil mulheres ao ano no mundo.

\section{REFERÊNCIAS}

1. ALBORGHETTI G, et al. Frequência de Gardnerella vaginalis em esfregaços vaginais de pacientes histerectomizadas. Revista da Associação Médica Brasileira, 2007; 53:162-165.

2. ALMEIDA MS, et al. Prevalência de microrganismos patogênicos presentes em secreções vaginais de pacientes atendidas na Unidade de Saúde de Mazagao-AP/Brasil no Ano de 2009 E 2010. Revista de Biologia e Ciências da Terra, 2013; 13: 80-86.

3. ALVES J, et al. Exame colpocitológico (papanicolau): O conhecimento das mulheres sobre o preventivo no combate do câncer de colo do útero. Revista Faculdade Montes Belos (FMB), 2016; 9:125-141.

4. AMARAL AD. Incidência de Gardnerella vaginalis nas amostras de secreção vaginal em mulheres atendidas pelo laboratório municipal de Fraiburgo. Rev. Ciênc. Farm. Básica Apl, 2012; 33 (33): 455-458.

5. AMERICAN COLLEGE OF OBSTETRICS AND GYNECOLOGY. Vaginitis. Int. J. Gynecol. Obstet, 1996; 53:271-280.

6. BOATTO HF, et al. Correlação entre os resultados laboratoriais e os sinais e sintomas clínicos das pacientes com candidíase vulvovaginal e relevância dos parceiros sexuais na manutenção da infecção em São Paulo.Brasil. Ver Bras Ginecol Obstet, 2007; 29:80-4.

7. BRASIL. Ministério da Saúde. Secretaria de Vigilância em Saúde. Departamento de DST, Aids e Hepatites Virais. Protocolo Clínico e Diretrizes Terapêuticas para Atenção Integral às Pessoas com Infecções Sexualmente Transmissíveis/Ministério da Saúde, Secretaria de Vigilância em Saúde, Departamento de DST, Aids e Hepatites Virais, Brasília: Ministério da Saúde, 2015;122 p.

8. BROOKS SLK, RODRIGO S. Prevalence of bacterial vaginosis in Grenadian women of reproductive age. West Indian Med J, 2013;62(7): 599-603.

9. CARVALHO JAM, BRITO F. A demografia brasileira e o declínio da fecundidade no Brasil: contribuições, equívocos e silêncios. Revista Brasileira de Estudos Populacionais, São Paulo, 2005; 22 (2): 351-370.

10. CARVALHO MGD. Presença de $20 \%$ ou mais de cluecells como um critério diagnóstico de vaginose bacteriana em esfregaços de Papanicolau. Dissertação (Mestrado em Tocoginecologia)-Instituto de Ciências Biomédicas. Universidade Estadual de Campinas, São Paulo, 2005; 51 p.

11. DE LIMA EA, et al. A utilização de probióticos como terapia complementar em mulheres com HPV. Encontro de Extensão, Docência e Iniciação Científica (EEDIC), 2019; 4p.

12. DUARTE G, LANDRES DV. Vulvovaginites - Aspectos Epidemiológicos. J Bras Doenças sexualmente Transmissíveis, 1998; 10(5): 4-14.

13. DUARTE G, et al. Fisiopatologia, diagnóstico e tratamento da vaginose bacteriana. Braz. J. of Develop., Curitiba, 2019; 5: 21467-21475.

14. FEBRASGO - FEDERAÇÃO BRASILEIRA DAS ASSOCIAÇÕES DE GINECOLOGIA E OBSTETRICIA. 2010. In: Manual de Orientação em Trato Genital Inferior e Colposcopia. São Paulo. Disponível em: https://www.febrasgo.org.br/images/arquivos/manuais/Manual_de_Patologia_do_Trato_Genital_Inferior/ManualPTGI-Cap-06-Vulvovaginites.pdf.Acesso em: 8 dez. 2020. 
15. FELIX TC. Vulvovaginite em mulheres atendidas em serviço de Atenção Primária à Saúde da Família: ocorrência e hábitos de higiene. Dissertação (Mestrado em Ciências da Saúde) - Universidade Federal de Uberlândia, Uberlândia, 2019; $78 \mathrm{f}$.

16. FERRIS MJ, et al. Association of Atopobium vaginae, a recently described metronidazole resistant anaerobe, with bacterial vaginosis. BMC Infect Dis; London, 2004; 4:5-10.

17. FIGUEIREDO PG. Redução da expressão da ciclo-oxigenase-2 em lesões precursoras do câncer do colo uterino em mulheres com vaginose bacteriana. (Tese de Doutorado)- Faculdade de Ciências Médicas da Universidade Estadual de Campinas, São Paulo, 2006; 84 p.

18. GOJE O, MUNOZ JL. Vulvovaginitis: Find the cause to treat it. Cleveland Clinic Journal of Medicine, 2017; 84: 215224.

19. HARRIOT MM, et al. C. albicans forms biofilms on the vaginal mucosa. Microbiology, 2010;156: 3635-44.

20. KONEMAN EW, et al. Diagnóstico microbiológico: texto e atlas colorido. 6. ed. Rio de Janeiro: Guanabara Koogan; 2008.

21. LARSSON PG, et al. Bacterial vagionisis adisturbed bacterial flora and treatment enigma. APMIS, 2005; 113:305-16.

22. LEITE SRRF, et al. Perfil clínico e microbiológico de mulheres com vaginose bacteriana. Rev. Bras. Ginecol. Obstet., Rio de Janeiro, 2010; 32: 82-87.

23. LEPARGNEUR JP, ROSSEAU V. Protective role of the Doderlein flora. J Gynecol Obstet Biol Reprod, 2002; 31:48594.

24. LINHARES IM, et al. Novos conhecimentos sobre a flora bacteriana vaginal. Rev. Assoc. Med. Bras., São Paulo, 2010; 56: 370-374.

25. MICHELIM L. Abordagem Biotecnológica em Proteus mirabilis. (Tese ao Programa Programa de Pós-Graduação em Biotecnologia)-Universidade de Caxias do Sul; 2008.

26. MOODLEY P, et al. Interrelationships among Human Immunodeficiency Virus type 1 Infection, Bacterial Vaginosis, Trichomoniasis, and the presence of yeasts. J Infec Dis, 2002; 185: 69-73.

27. NICOLETTI GP. Prevalência e fatores associados à Gardnerella vaginalis em mulheres atendidas em clínica ginecológica no município de Natal RN / Giancarlo Paiva Nicoletti-Natal, 2019; 49f.

28. NUGENT RP, et al. Reliability of diagnosing bacterial vaginosis is improved by a standardized method of gram stain interpretation. J Clin Microbiol,1991; 29:297-301.

29. NUNES RD, et al. Prevalência de Vulvovaginites na Gestação e sua Associação Com Complicações Perinatais. Arq. Catarin Med, 2018; 47:121-132.

30. OLIVEIRA AB, et al. Prevalência de Gardnerella e Mobiluncus em exames de colpocitologia em Tome-Açu, Pará. Rev Para Med, Belém, 2007; 21:47-51.

31. PAAVONEN J, BRUNHAM RC. Bacterial Vaginosis and Desquamative Inflammatory Vaginitis. N Engl J Med, 2018; 379:23.

32. PALADINE HL, et al. Vaginitis: Diagnosis and Treatment. American Family Physician, New York, 2018; 97: 321 -329.

33. RESENDE AF, et al. Prevalência de vaginoses bacterianas em pacientes que realizaram bacterioscopia de secreção vaginal Rev. Ciênc. Méd. Biol., Salvador, 2019;18:190-193.

34. RIBEIRO AA, et al. Agentes microbiológicos em exames citopatológicos: estudo de prevalência. Ver Bras Anál Clín, 2007; 39: 179-81.

35. RODRIGUES MT, et al. Associação entre cultura de secreção vaginal, características sociodemográficas e manifestações clínicas de pacientes com diagnóstico de candidíase vulvovaginal. Revista Brasileira de Ginecologia e Obstetrícia, 2013; 35: 554-561.

36. SHIPITSYNA E, et al. Quantitation of all four Gardnerella vaginalis clades detects anormal vaginal microbiota characteristic of bacterial vaginosis more accurately than putative $\mathrm{G}$. vaginalis Sialidase A gene count. Mol. Diagn, 2019; 23: 139-147.

37. SILVA CHPM, et al. Bacteriologia e micologia. Rio de Janeiro: Revinter; 2006.

38. TONINATO LG, et al. Bacterial vaginosis diagnosed in routine cytology tests: prevalence and characteristics of Papanicolaou smears. RBAC, 2016; 48:165-9.

39. WITKIN SS. Immunology of recurrent vaginitis. Am J ReprodlmmunolMicrobiol, 1987; 15:34-7. 